\title{
A VIOLÊNCIA NA HISTÓRIA E A LEGITIMIDADE DA DESOBEDIÊNCIA CIVIL
}

\author{
Helenice Rodrigues da Silva*
}

\begin{abstract}
RESUMO
Tradicionalmente assimilada à noção de poder, a violência inscreve-se, comumente, na crítica platoniana do "tirano", no maquiavelismo do "príncipe" e na crítica marxista de dominação. Em termos de opressão, o sistema colonialista e as guerras coloniais (da segunda metade do século $\mathrm{XX}$ ), reativando a questão da violência na história, trazem à tona a realidade de opressão dos povos colonizados. Através da abordagem da temática da desobediência civil, durante a guerra da Argélia, este artigo tenta apreender uma outra dimensão da violência na política: aquela que reage à "violência primeira", que é o próprio sistema.
\end{abstract}

Palavras-chave: colonialismo, engajamento, desobediência civil.

\begin{abstract}
Traditionally assimilated to the concept of power, violence usually lies within the frameworks of Plato's critique of the "tyrant", of the "prince's" Machiavellanism and of Marx's critique of domination. In terms of oppression, the colonialist system and the colonial wars (during the second half of the $20^{\text {th }}$ century) testify to the violence unleashed in the history of colonized peoples. By adopting an approach linked to the theme of civil disobedience during the Algerian war, this article tries to apprehend another dimension of violence: that dimension which reacts to "primary violence".
\end{abstract}

Key-words: colonialism, commitment, civil disobedience.

* Professora Adjunta da Universidade Federal do Paraná. 


\section{Observações preliminares}

"Que a violência tenha existido sempre, em toda parte, é algo que não se contesta, quando pensamos na maneira pela qual se edificam e se desmoronam os impérios, se firmam os prestígios pessoais, se entre-devoram as religiões, se perpetuam ou se derrubam os privilégios da propriedade e do poder, e até mesmo como se consolida a autoridade dos mestres do pensamento." Essa citação de Paul Ricoeur, extraida do livro História e verdade, publicado em 1957, ou seja, pouco após a insurreição de Budapeste (em novembro de 1956), ${ }^{2}$ violentamente reprimida pelos tanques soviéticos, e em plena guerra da Argélia, atesta a íntima relação que o poder entretem com a violência.

As "chamas de Budapeste", ${ }^{3}$ abalando as convicções ideológicas dos intelectuais da esquerda francesa, inspiram Ricoeur a elaborar uma reflexão sobre a problemática do poder. A originalidade dupla e paradoxal do político residiria, segundo esse autor, na sua racionalidade específica e nas suas possibilidades de perversão.

Antes de entrarmos na análise do nosso objeto propriamante dito ("a desobediência civil, durante a guerra da Argélia, contra a violência do Estado francês"), algumas constatações iniciais nos parecem pertinentes.

Em primeiro lugar: a violência, associada à idéia do poder político, aparece como intrínseca à origem e à natureza de todo poder. "O Estado, segundo Weber, detém o monopólio da violência legítima. Nessa perspectiva, a força e sua extensão, a guerra, é passível de permanecer sempre no horizonte do poder." ${ }^{4}$ Podemos, nesse caso, associar o político à idéia de violência legítima e legal? Tito Lívio (Discurso sobre a primeira década

1 RICOEUR, P. História e verdade. Rio de Janeiro: Forense, 1968. p. 227.

2 A violenta repressão sovética, resultando na prisão de intelectuais e de estudantes húngaros, marcou uma primeira ruptura, por parte da classe intelectual francesa, em relação ao partido comunista francês e à política de Moscou.

3 Título de seu artigo publicado na revista Esprit e inserido na segunda edição de História e verdade. "O evento de Budapeste, como todo evento dígno desse nome, tem um poderio indefinido de abalo; tocou-nos e comoveu-nos em diversos de nossos níveis: o nível de sensibilidade, ferida pelo inesperado; o nível do cáculo político a meio termo; o nível da reflaxão duradoura sobre as estruturas políticas da existência humana”. (História e verdade, p. 251).

4 SPECTOR, C. Le pouvoir. Paris: Corpus/GF Flammarion, 1997. p. 228. 
de Tito Lívio, I, 9) já dizia que era preciso condenar "não a violência que restaura, mas a violência que ruína." ${ }^{5}$ Em geral, a argumentação em defesa da violência se faz segundo a fórmula: "os meios justificam o fim”. Isso pressupõe a possibilidade de aceitar a violência do Estado que, perdendo seu "caráter passional, imprevisível, desproporcional, transforma-se em racional, previsível e calculado" (Spector).

Em segundo lugar: a visão marxista, justificando a violência como motor da história, opõe-se à ótica voluntarista da violência do político. Dentro dessa perspectiva, a violência pode parecer racional, se seu objetivo consiste em ir além da própria violência, que é a exploração do homem. ${ }^{6}$

Em sua obra Filosofia política, ${ }^{7}$ que pensa a questão da violência, Éric Weil, retomando a leitura de Hegel, afirma: "a violência foi e ainda é a causa motora da história e, no entanto, ela é a consciência política que busca o progresso em vista da eliminação da violência, eliminação que é sua causa final: o consciente não origina do consciente mas de seu contrário, e a vontade da paz nasce da guerra e da luta."

Em terceiro lugar: o papel da violência na fundação das identidades, principalmente coletivas, não pode ser ignorado e passado em silêncio. Por trás dos abusos (instrumentalizações ou manipulações) da memória, encontra-se, na maioria das vezes, a relação fundamental da memória com a violência. Dificilmente encontramos uma comunidade histórica que não tenha sido originária de uma relação assimilada à guerra. As chamadas "feridas coletivas", ilustradas através de determinados acontecimentos históricos, como: a descoberta da América em 1492 e o genocídio indígena que a acompanha, assim como as guerras coloniais em países africanos, enquadram-se nessa categoria. O que se celebra sob a designação de "acontecimentos fundadores" são, na sua essência, atos violentos legitimados, posteriormente, por um Estado de direito precário. ${ }^{9}$

5 SPECTOR, op. cit., p. 228.

6 Ibid., p. 229.

7 WEIL, E. Filosofia política. Paris: Vrin, 1956.

8 Filósofo francês, de origem judia e alemã, Weil (1904/1977) foi discípulo de Ernst Cassirer. Instalando-se na França, em 1933, ele prossegue sua linha kantiana, trabalhando com a filosofia moral e política. Essa citação de Éric Weil é extraida do texto de BURGIO, A. Du discours à la violence. In: DISCOURS, violence et langage, un socratisme d'Éric Weil? Le Cahier, Collège International de Philosophie, n. $9 / 10$, p. $232-233,1990$.

9 Ver RICOEUR, P. Entre mémoire et histoire. Projet, n. 248, p. 12, 1996. 


\section{O diálogo e a discussão como prática política}

A fim de melhor ilustrar a relação da violência com a história, propomos abordar a temática da desobediência civil, durante a guerra da Argélia (1954/1962), como forma de reação à violência do sistema político. No entanto, convém precisar que essa guerra, engendrando engajamentos por parte dos intelectuais franceses da esquerda, propicia, no "espaço público", um vasto debate de idéias. O diálogo e a discussão transformam-se, ao longo da duração desse conflito, em uma prática política. Embora o cambate à guerra da Argélia envolva, praticamente, todos os segmentos da esquerda intelectual, a chamada esquerda progressista, liderada pelos sartrianos e pelos membros da revista Les Temps Modernes, fazem desse conflito uma verdadeira batalha contra a política da IV e da V República Francesa.

A pressão exercida pela política sobre a vida intelectual, tendo por resultado o engajamento, obriga o intelectual a escrutar todas as conseqüências políticas de suas escolhas filosóficas, assim como a fundar filosoficamente suas escolhas políticas.

Embora não pretendendo elaborar uma análise filosófica sobre a violência na história, não podemos deixar de mencionar o fascínio exercido por Hegel sobre a esquerda intelectual francesa, que, através do ensino de Kojève, inspirou uma leitura da história a partir dessa perspectiva. Sem dúvida, a geração de Sartre sofreu uma forte influência da redescoberta do pensamento hegeliano, sobretudo através dos cursos de Alexandre Kojève, ${ }^{10}$ ministrados na École Pratique des Hautes Études, de 1933 a 1939. Entre os diversos participantes desses seminários encontravam-se as grandes figuras da "intelligentsia" da época: Sartre, Merleau-Ponty, Simone de Beauvoir, Raymond Aron, Georges Bataille, Jacques Lacan, entre outros. Consagrado essencialmente à leitura da Fenomenologia do espírito (ainda não traduzido em francês), esse curso centrava-se no tema do "fim da história". Nesse contexto dos anos 30, marcado pela ascensão dos fascismos, a assimilação das lições de Hegel pelos intelectuais franceses deixou marcas profun-

10 Filósofo russo, emigrado na França no início dos anos 30 (anti-staliniano mas hegeliano). 
das na produção intelectual. O hegelianismo de esquerda privilegiava uma leitura da História, fundada na idéia da violência e nas relações de força. Kojève insistia, particularmente, na concepção da História como "lugar da violência". Mais do que a razão, as lutas sangrentas fazem avançar a História em direção a um desfecho positivo. Essa "concepção terrorista da História", sem dúvida, influenciou um Merleau-Ponty ao escrever o texto "Humanismo e terror" (Les Temps Modernes, 1947) e um Sartre no momento em que faz a apologia da violência, no prefácio ao livro de Frantz Fanon, Os condenados da terra, em 1961. ${ }^{11}$

\section{Discurso e violência: o discurso sobre a violência}

A ação dos intelectuais de esquerda durante a guerra da Argélia visa não só a combater essa guerra, mas a revelar à opinião pública francesa a verdadeira face do colonialismo. Denunciando, em meio às malhas da censura, esse sistema anacrônico de dominação e de opressão, os intelectuais realizam um verdadeiro ato de oposição política. Os jornais e as revistas intelectuais de esquerda denunciam o uso da força, por parte das autoridades francesas na Argélia, que se servem de instrumentos de coerção (a tortura, por exemplo) para impedir a vitória do "inimigo" político. Dois momentos particulares marcam o engajamento dos intelectuais durante essa guerra colonial: o primeiro, durante a campanha contra a tortura em 1957, o segundo, em 1960, a favor da insubmissão dos jovens franceses recrutados para combater na Argélia.

Junto a outros intelectuais de renome (François Mauriac, Roger Martin du Gard, prêmios nobel de literatura, entre outros), Sartre engaja-se efetivamente no combate contra a tortura (praticada pelo exército francês), redigindo prefácios de livros, artigos e manifestos sobre essa "questão". ${ }^{12}$

11 Ver SILVA, H. R. da. Texte, action et histoire-réflexions sur le phénomène de l'engagement. Paris: L'Harmattan, 1995.

12 Sob a designação de "a questão", os intelectuais revelam a prática da tortura na Argélia. Henri Alleg publica, em 1958, o livro La question, cujo prefácio é escrito por Sartre. 
Na lógica da literatura engajada sartriana, "falar" significa "agir"; a palavra é um ato e uma ação em direção ao outro. O discurso deve agir sobre o público, produzindo nele um efeito positivo: persuadí-lo da legitimidade da "causa" defendida. ${ }^{13}$ Servindo-se de uma grade de leitura existencialista, Sartre faz apelo à "ética de responsabilidade" na sua argumentação contra essa "prática abjeta".

Não é sabotando, em princípio, sua moral que se desmoraliza uma nação, é abaixando sua moralidade, quanto ao procedimento todo mundo conhece, precipitando-nos numa aventura abjeta, colocaram-nos uma culpabilidade social (...). Os crimes que se cometem em nosso nome nos tornam pessoalmente cúmplices, pois nos resta o poder de colocarmos um ponto final. ${ }^{14}$

A condenação é assim julgada em relação a uma das premissas do engajamento intelectual: "a ética de responsabilidade".

Em relação ao prefácio do livro de Frantz Fanon, ${ }^{15}$ esse texto atinge o paroxismo da escrita engajada sartriana em direção ao outro, ou seja, ao Terceiro Mundo. Como em todo discurso ideológico, a violência encontra-se presente e subentende na sua lógica interpretativa a demonstração de uma "verdade". A linguagem torna-se, em decorrência, o próprio lugar da violência. Na verdade, o discurso terceiro-mundista (dos países descolonizados) configura-se a partir de uma espécie de mitologia niilista do ego, na qual o problema do espaço vital está ligado à idéia da eliminação do outro.

Nesse prefácio, Sartre declara:

...quando os campesinos pegam o fusil, os velhos mitos empalidecem, os interditos, um por um, são invertidos: a arma

13 Ver SILVA, H. R. da. Le discours d'Esprit et des Temps Modernes contre la guerre d'Algérie - réflexions sur le phénomène de l'engagement. Nanterre, 1991. Thèse (Doctorat d' Etat) - Université de Paris X. 2 volumes.

14 Cf. SARTRE, J-P. Situations V-colonialisme et néo-colonialisme. Paris: Gallimard, 1964, p. 67.

15 FANON, F. Les damnés de la terre. Paris: Maspéro, 1961. (traduzido e publicado em português). 
de um combatente é sua humanidade. Pois, em um primeiro momento da revolta, é preciso matar: eliminar um europeu significa dar, com uma pedra, dois golpes, suprimir ao mesmo tempo um opressor e um oprimido, permanecendo [assim] um homem morto e um homem vivo; o sobrevivente, pela primeira vez, sente um solo nacional sob a sola de seus pés. ${ }^{16}$

Toda a análise sartriana sobre o colonialismo e suas variantes (o racismo, por exemplo) inspira-se na dialética hegeliana do "maître et l'esclave" (o senhor e o escravo). Essa dialética fenomenológica permite pensar, em geral, o tema da opressão e, em particular, o tema da "luta das consciências afrontadas entre elas pelo seu reconhecimento mútuo" (Delacampagne). Transposto ao contexto das lutas pela descolonização, esse modelo permite radicalizar a denúncia do sistema colonialista. Ao longo desse conflito, Sartre esforça-se em provar, pelo viés de um raciocínio dialético (o colonizador e o colonizado), a impossibilidade e a ineficácia de todo e qualquer programa de reforma na Argélia. A única solução possível é, segundo ele, a independência incondicional do povo argelino. Se Sartre faz apelo à lógica dos opostos (opressor/oprimido) é para melhor demonstrar as contradições insuperáveis entre os interesses dos colonos e os dos colonizados. A intriga, baseada na dicotomia dominante/dominado, permanece nesses escritos sempre invariável embora mudem os atores. ${ }^{17}$

No pensamento revolucionário francês nos anos 50/60, os "condenados da terra" deixam de ser os operários (dos países industrializados), transformando-se em novas vítimas da opressão: os colonizados do Terceiro Mundo que Sartre designa de "sub-homens".

Ao contrário de uma parte da esquerda, adepta do reformismo, ${ }^{18}$ Sartre reivindica, desde o início da guerra da Argélia, a independência como condição prévia à toda negociação. Desvendando nos seus primeiros textos suas simpatias pela causa argelina, ele antecipa, desse modo, suas tomadas de posição futuras em favor das "redes de apoio intelectual à Frente de Liberação Nacional" (FLN).

16 SARTRE, op.cit., p. 183-184.

17 Ver SILVA, 1995, op.cit.

18 De inspiração humanista cristã, o reformismo implicava na idéia de uma eminente reforma, de mudanças (políticas, sociais e econômicas) na Argélia, como meio de se preservar a continuidade do sistema colonial. 
Nesse momento de intensa mobilização dos intelectuais franceses contra a guerra da Argélia, a ação ou a práxis manifesta-se através do discurso; a palavra torna-se, dentro dessa noção do engajamento, sinônimo de um ato político. "A moralização do mundo passa pela ação política", afirma Éric Weil (Filosofia política). Na tradição filosófica, essa concepção de ação intelectual remete ao diálogo do filósofo na "pólis" ("forum público"), remontando à perspectiva socrática. A dimensão política da atividade filosófica, como sabemos, encontra-se essencialmente ligada à educação e à discussão, que Weil chama de "diálogo", ou seja, de um ato político. ${ }^{19}$ Analisando a violência como problema para a filosofia (o diálogo sendo o domínio da não-violência), Weil atesta que ela é somente um meio tecnicamente necessário, em um mundo que ainda se encontra sob a lei da violência, para criar um estado de não-violência.

A violência primeira não é o conteúdo da vida humana, ao contrário, a vida humana só terá conteúdo humano a partir do momento em que a violência segunda, dirigida contra a violência primeira pela razão e pela idéia de coerência, terá eliminado essa última do mundo e da existência do homem: a não-violência é o ponto de partida como o ponto final da filosofia. ${ }^{20}$

O contexto histórico - de anacronismos e de dominações inscrito na guerra colonial - propicia ocasião para o intelectual ocupar a cena pública, reativando, através da prática, do diálogo e da discussão, a tradição filosófica helênica.

19 Ver DISCOURS, violence..., op. cit., p. 11-12.

20 WEIL, E. Logique de la philosophie. 2. ed. Paris: Vrin. p. 59. 


\section{A violência como problema para o filósofo}

Desde o final do ano de 1957, uma "rede de ajuda ao FLN", composta em grande maioria por jovens comunistas, pela esquerda cristã e por sindicalistas, é organizada em toda a França sob a direção do filósofo e colaborador de Le Temps Modernes, Francis Jeanson. Entrando na clandestinidade, Jeanson e outros membros dessa rede colaboram com os argelinos (transportando dinheiro e dando alojamento aos responsáveis dessa frente). A descoberta da existência dessa rede de apoio aos combatentes argelinos, em fevereiro de 1960, através do noticiário da prisão de vários de seus membros, provoca, junto à mídia, à opinião pública e aos intelectuais, impactos e polêmicas. A revelação da existência das redes de apóio ao FLN e de casos de refratários (deserção de uma parte de jovens soldados franceses convocados para a guerra) engendra um amplo debate de idéias na imprensa e no seio dos partidos políticos.

Com excessão da revista Les Temps Modernes, toda a impressa francesa e os partidos da esquerda condenam, por unanimidade, esses "atos terroristas". No entanto, se analisarmos mais detalhadamente essas críticas, constatamos que, por detrás das condenações feitas a essa "inteligência em ação", buscam interpretar a eficácia de uma ação intelectual. Essas ações radicais (a passagem ao ato), que revelam a transgressão dos interditos tradicionais, conduzem os intelectuais engajados a se posicionarem frente às contradições inelutáveis de uma ação intelectual e das inevitáveis aporias entre a palavra e a práxis.

A publicação na revista Esprit (esquerda cristã) e em Les Temps Modernes de artigos, de respostas, de citações de jornais, de cartas de leitores atesta a efervecência intelectual que traduz a importância da discussão intelectual no "forum público". Na verdade, a modalidade desses debates, ou seja, dessa prática discursiva (em forma de um diálogo indireto) revela que esses discursos não passam de meta-discursos. Os jornalistas e intelectuais se dirigem mais a seus pares do que aos respectivos leitores. Para tentar convencer seus interlocutores da legitimidade de suas teses, essas duas revistas adotam estratégias diversas (polêmicas e persuasivas). ${ }^{21}$

21 Ver SILVA, H. R. da. Les temps de l'action. Le discours d'Esprit et des Temps Modernes sur les réseaux de soutien au FLN et les mouvements des insoumis. Hermès, Éditions du CNRS, n. 8/9, 1991. 
Nas análises elaboradas pelos intelectuais da esquerda em torno dessas ações de "resistências" (rede de apóio dos intelectuais franceses ao FLN e deserção de soldados), a questão da legitimidade da violência e sua relação com a História assume, portanto, a forma de um debate filosófico. A propósito, o responsável pela revista Esprit (Jean-Marie Domenach) distingue, nessas ações, dois tipos de situações: as tributárias de uma "ética de sofrimento" ("éthique de détresse") e que são da ordem da "não-violência"e as que se inscrevem no quadro da violência. Fazem parte da primeira categoria: a deserção de soldados recrutados que recusam combater na Argélia" e "o alojamento de argelinos procurados pela polícia".

Essas ações "não-violentas" visam a "remediar as injustificáveis violências", a saber: a prática da tortura cujas vítimas são os prisioneiros argelinos e a repressão exercida em relação aos soldados franceses desertores.

Cada pessoa tem o direito e mesmo o dever de remediar [essas violências] através de próprios meios, mesmo indo contra leis escritas e mesmo que tais ações tragam um certo reconforto à causa do FLN (...). A ajuda direta dada ao FLN (propaganda e outros serviços) é de uma outra natureza. Não se trata mais da reparação não violenta de uma ordem, mas de uma participação deliberada a um empreendimento, por si mesmo violento, político e militar, que se encontra em conflito com o político e com o exército da França. Nós sempre desaprovamos tais atos. ${ }^{22}$

O problema da legitimidade da violência e sua relação com a História coloca-se através das seguintes questões: o sofrimento vivido por um povo justifica o direito à violência? Recusar as leis injustas significa exercer a violência? O tema da violência ocupa um vasto espaço nas discussões intelectuais, tornando-se um dos lugares de diferença entre a esquerda intelectual moderada e a esquerda intelectual progressista. ${ }^{23}$ É exatamente em torno de questões de ordem filosófica que, num primeiro momento, se articula a maior parte das discussões sobre as redes de apóio ao

22 DOMENACH, J-M. Sauve qui peut? Esprit, p. 707, avr. 1960. Ver em ibid., p. 180.

23 Ver SILVA, 1991, op. cit., p. 179-180. 
FLN e os casos de insubmissão, razão pela qual os discursos fazem uma referência, implícita e explícita, ao drama de Antígona.

Maurice Duverger, por exemplo, em um artigo publicado no jornal Le Monde,$^{24}$ levanta e seguinte questão: em caso de uma injustiça flagrante, podemos substrair habilmente do drama de Antígona um símbolo antigo de um conflito sempre atual? Frente a uma guerra injusta, os indivíduos têm o direito de transgredir as "leis escritas", estabelecidas pela justiça e preconizar, à sua maneira, as leis não escritas? É a partir de princípios morais, de considerações sobretudo éticas, que os intelectuais, hostís a essas ações radicais, posicionam-se sobre a questão da práxis política. Sem dúvida, essa discussão é tributária de "valores", ou seja, de princípios próximos da norma e da moral, o que explica a tendência à elaboração de um discurso, em suma, moralista.

"O pertencimento a uma comunidade nacional implica em uma obrigação de solidariedade que assume várias formas (jurídica, política, moral)", afirma Domenach na revista Esprit..$^{25}$ Esse argumento é utilizado por parte dos intelectuais para justificar sua condenação às ações de resistência , que, segundo eles, ilustram "a transgressão das regras fundamentais de civismo".

Apesar de a França reprimir uma revolta justa servindo-se de métodos indignos, Esprit insite que não se deve "lutar pela vitória do campo oposto", mas combater na própria França para o sucesso de uma paz negociada. "É preciso uma regra [de ação] e essa regra não pode ser a de agir contra as regras, pelo menos enquanto existir possibilidades de agir dentro das regras." ${ }^{26}$ Segundo Esprit, essa forma de engajamento individual na clandestinidade (a ação do filósofo Jeanson) não pode ser eficaz e a ação desse último não pode pretender ser um ato político, ele é muito mais um ato de testemunho. te maneira:

As posições defendidas por Esprit podem ser resumidas da seguin-

1 - as ações clandestinas visam a proclamação da "ilegalidade do poder";

24 DUVERGER, M. Les deux trahisons. Le Monde, 27 avr. 1960.

25 DOMENACH, op. cit., p. 708.

26 Ibid., p. 710. 
2 - essas ações se revelam ineficientes do ponto de vista político e se inscrevem no quadro da violência;

3 - a deserção é um assunto de consciência, mas que não será propagado pela revista;

4 - as ações não-violentas, no plano espiritual (manifestações silenciosas contra a guerra), devem ser elaboradas no interior de um movimento popular e constituirem novas resistências.

\section{A violência primeira: o colonialismo}

Ora, como conciliar, nesses tempos de guerra, atitudes puramente morais à realidade política? No fundo, as discussões levantadas pela revista Esprit, ressaltam duas concepções de ação em função da realização de um discurso coerente e, que remete à própria tarefa do filósofo e do "homem de ação" (o político), a saber, aquele que pensa a ação e aquele que age na ação.

O debate em torno das ações de resistências contra a guerra da Argélia, centrado na questão da violência, remete-nos às análises de Éric Weil (Lógica da filososfia), que, por sua vez, reporta-se ao discurso da violência desenvolvida por Hegel e que faz uma leitura da violência como problema para a filosofia. Segundo Weil, a violência é um meio "tecnicamente necessário num mundo que ainda se encontra sob a lei da violência, para criar um estado de não-violência." ${ }^{27} \mathrm{Se}$ a violência constitui a reação à violação da humanidade do homem, ela aparece legítima, pois necessária em si. Para Weil, a dialética entre "discurso e violência" é o fio condutor do devir das comunidades dos homens e da própria razão. A violência possível é o motor de um movimento cujo objetivo consiste em ir além da própria violência. A violência é ilegítima quando as exigências que a motivam não são gerais ou generalisáveis. Ao contrário, toda a forma de violência que se apoie em razões universais, ou seja, que reage à violação das razões universais, é, segundo Weil, justificável. Em outras palavras, a violência se justifica quando ela 
se opõe à negação da humanidade do homem, a violência é legítima quando ela reage a uma violência que nega o homem enquanto homem.

Se Esprit privilegia o aspecto moral nas suas discussões, Les Temps Modernes, ao contrário, acentua o caráter político dos atos de insubmissão e de apoio ao FLN. O artigo de Marcel Péju (redator-chefe, desta última), enfatizando o aspecto prático da noção de ação, reafirma a posição estratégica da revista: solidariedade efetiva com os combatentes argelinos. Aliás, o título desse artigo - "A esquerda respeitosa" 28 é extremamente sugestivo, pois ela faz diretamente alusão à peça de teatro escrita por Sartre - "A prostituta respeitosa". Se Péju questiona a dimensão e o significado desses "acontecimentos" é, sobretudo, para mostrar o fracasso e a impotência da esquerda política. A rede Jeanson, a insubmissão, desenvolvidos à margem dos partidos políticos, são, segundo Les Temps Modernes, um sintoma e uma advertência: "o tempo de respeito terminou." 29

As principais posições da revista de Sartre sobre as ações de resistência podem se resumir da seguinte maneira:

1 - para além de uma eficácia real, a ação de apoio ao FLN tem um significado político, na medida em que ela responde às carências da esquerda política. Essas ações não são uma simples reação de ordem sentimental, apesar de seu caráter limitado e do isolamento de Jeanson, sua ação visa o devir.

2 - " ninguém tem o direito de incitar os jovens soldados a desobedecer [as ordens do exército], a não ser os próprios." No entanto se, pelo momento, um tal apelo não constitui uma palavra de ordem, ele não é algo inconcebível. ${ }^{30}$

Apesar das diferenças de posição entre a esquerda moderada e a esquerda progressista (a primeira adepta da não-violência, a segunda favorável à "violência segunda" como resposta à "violência primeira"), ambas concordam em reconhecer o caráter intrínseco da violência: do colonialismo. Objeto de um consenso geral por parte de toda a esquerda anticolonialista, a crítica a essa violência inicial exprime-se por meio de modalidades discursivas distintas. Os adeptos da não-violência, embora critiquem a vio-

28 PÉJU, M. A esquerda respeitosa. Les Temps Modernes, avr./mai 1960.

29 Ibid., p. 1529.

30 Id. 
lência primeira, não reconhecem a legitimidade do combate dos argelinos, recusando os meios adotados por "aqueles" que reagem à violência. Os partidários da legitimidade da "violência segunda", como resposta à violência do colonialismo e da guerra, consideram injustificável a condenação do terrorismo do FLN.

\section{A desobediência civil ou o direito à insubmissão: o "Manifesto dos 121"}

Na medida em que esse manifesto, redigido no momento do processo Jeanson (setembro de 1960), encarna um projeto simbólico de ação, ele se transforma em emblema do movimento de resistência contra a guerra da Argélia. Se esse manifesto é uma resposta aos problemas levantados, anteriormente, sobre a "insubmissão" e as redes de apoio ao FLN, ele não deixa de ser também uma forma de reação a uma situação política que parece bloqueada, sobretudo após o fracasso das negociações de Melun. ${ }^{31} \mathrm{O}$ "manifesto ao direito à insubmissão" corresponde, na verdade, a uma reativação e a um ultrapassamento da ação intelectual, até então exprimida sob a forma de um protesto moral e político. Frente aos impasses políticos e a uma guerra que parece se eternizar, a esquerda intelectual progressista justifica a necessidade de radicalizar suas ações.

"Diante dos graves problemas colocados pela continuidade do conflito argelino, 150 personalidades [no início 121] tomaram para si a responsabilidade de uma declaração sobre o direito de insubmissão na guerra da Argélia", escreve Les Temps Modernes, em um número especial (agosto/ stembro de 1960). Como a publicação do texto é interditada pelo governo francês, Les Temps Modernes e o jornal Le Monde publicam apenas pequenos trechos do manifesto. As duas primeiras páginas, deixadas em branco,

31 Essas negociações entre o governo francês e os responsáveis argelinos do FLN, na cidade de Melun, França, ocorreram no início de 1960. 
seguidas pela lista dos assinantes, constitui um desafio extremamente simbólico por parte da revista sartriana. Le Monde de 6 de setembro publica, entretanto, as afirmações seguintes, que figuram no final desse manifesto:

- Nós recusamos e julgamos lícita a recusa de combater pela arma o povo argelino.

- Nós respeitamos e julgamos justificadas a conduta dos franceses que consideram que é de seu dever ajudar e proteger os argelinos, oprimidos em nome do povo francês.

- A causa do povo argelino, contribuindo de maneira decisiva para derrubar o sistema colonial, é a causa de todos os homens livres. $^{32}$

Concebido inicialmente como um "apelo à oposição internacional, pelas revistas Les Temps Modernes e Lettres Nouvelles, ${ }^{33}$ o manifesto dos " 121 " pode ser objeto de diferentes leituras. Se, incontestavelmente, ele é uma ilustração de solidariedade em relação aos intelectuais da rede Jeanson e aos desertores, esse manifesto não deixa de ser um desafio ético e um ato político contra a continuação da guerra da Argélia. Esse último aspecto, sem dúvida, contou para um certo número de assinantes que não dividiam todas as teses defendidas por Les Temps Modernes.

Detentores de um "capital cultural", os assinantes do manifesto formam essa "intelligentsia" de esquerda heterogênea, ${ }^{34}$ vinda de horizontes intelectuais os mais diversos. Além das equipes de redação das duas revistas (os surrealistas: de André Breton a Michel Leiris), encontramos todos os escritores do "Nouveau Roman", assim como alguns cristãos da esquerda, entre tantos outros.

O manifesto dos " 121 ", que também pode ser interpretado como uma recusa a todo moralismo abstrato, coloca implicitamente a questão do etc.

33 Revista literária tendo por colaboradores, Maurice Blanchot, Maurice Nadeau, André Breton

34 Cineastas da "nouvelle vague", artistas plásticos, de cinema e teatro etc. 
direito à desobediência civil contra o arbitrário e a violência, segundo uma perspectiva hegeliana. Se a violência constitui a reação às coerções e às opressões dos homens, ela é, portanto, legítima.

Esse ato de reconhecimento e de legitimidade das ações de resistência provoca reações de todas as partes. ${ }^{35}$ Por seu papel de detonador, o manifesto é de uma extrema eficácia simbólica. Em primeiro lugar, esse manifesto inflete sobre os dados do problema da insubmissão, levantados no início de 1960. Ele ressalta, além dos interesses específicos de cada campo (direita/esquerda), as oposições que separam as diversas frações da esquerda. Além disso, o manifesto provoca novos posicionamentos no interior do campo intelectual, obrigando uma parte dos intelectuais a deixarem o domínio do "não dito", do silêncio tácito, e a tomarem partido no debate público. As discussões se iniciam no seio dos partidos políticos de esquerda e novos manifestos (apoiando ou contestando os "121") se sucedem. Se o PSU (Parti Socialiste Unifié) se opõe à continuação da guerra da Argélia, ele recusa a insubmissão individual e a partida dos soldados recrutados do contingente. No entanto, por fidelidade aos princípios leninistas, o partido comunista se opõe à insubmissão em razão da sua própria concepção de luta armada; os soldados comunistas, escreve o jornal L'Humanité (16 de outubro de 1960), devem participar de todas as guerras, mesmo sendo elas reacionárias.

Em um artigo publicado na revista Esprit sobre a insubmissão, o filósofo Paul Ricoeur, aliás colaborador da revista e ligado intimamente à sua redação, delineia essa questão. "Não aconselho a insubmissão (...) mas recuso condená-la." ${ }^{36} \mathrm{Na}$ sua opinião, entre a esquerda intelectual e os insumissos existe uma mesma percepção no que diz respeito ao "profundo significado" da guerra: "guerra ilegal feita contra um povo que aspira sua liberação política". A recusa de Ricoeur a condenar a insubmissão, explica-se em razão da ineficácia do político ("a inércia da esquerda" e a perda de esperança do Estado concluir a paz pela negociação). Em contrapartida, o apelo à desobediência coloca o problema da ilegalidade do Estado e da ruptura com os mesmo. "Ora, apesar da ilegalidade fundamental da guerra

35 Essa lista repercute no estrangeiro, provocando a adesão de algumas personalidades, como: Primo Levi e Bertrand Roussel.

36 RICOEUR, P. Insoumission. Esprit, p. 1601, oct. 1960. 
(...), o Estado, escreve Ricoeur, tem uma base de lagalidade, uma forma constitucional (...) que ainda oferece recursos de ação legais." ${ }^{37}$

Em síntese, embora possa parecer um lugar comum, podemos afirmar que a violência na história faz parte da história da humanidade, estando intimamente associada à fundação das identidades de uma nação e às origens de uma comunidade. Tradicionalmente vinculada à concepção do poder e da força, a violência pode se explicar pelas instituições e pelas leis repressivas que constituem a forma usual de uma tal expressão (a violência). Mas, como bem observa Paul Ricoeur, devemos evitar a tentação de opor dois estilos de reflexão política, "um que supervaloriza a racionalidade do político, com Aristóteles, Rousseau, Hegel e outro que acentuaria a violência e a mentira do poder, segundo a crítica platoniana do 'tirano', a apologia maquiavélica do 'príncipe' e a crítica marxista da 'alienação política'." 38

O "hegelianismo de esquerda", na França, introduzido através da leitura de Hegel por Kojève, é tributário do contexto político dos anos 30 e do "campo" intelectual em luta pela hegemonia dos valores da esquerda. Apropriando, portanto, pelos intelectuais "progressistas", Hegel inspira interpretações, em suma, marxistas do "fim da história". Dentro dessa perspectiva, as lutas de classe e as lutas sangrentas, em geral, fazem avançar o curso da História em direção ao progresso. Essa lição, extrapolada à leitura da descolonização e das guerra coloniais, tende a legitimar o papel da violência como instrumento necessário às transformações das nações colonizadas. Desse modo, a guerra dos argelinos foi percebida, por uma fração da esquerda intelectual progressista, como "uma guerra contra outra guerra", ou seja, contra um sistema de exploração e de opressão. Dentro da lógica da violência, a vida de uns equivaleria à morte de outros, a emancipação política significaria o final de um regime de dominação. Guerra de liberação, o conflito argelino não teria nascido da idéia mesma da "não-violência"? 


\section{Referências}

BURGIO, A. Du discours à la violence. In: DISCOURS, violence et langage, un socratisme d'Éric Weil? Le Cahier, Collége International de Philosophie, n. 9/10, p. 232-233, 1990.

DOMENACH, J-M. Sauve qui peut? Esprit, p. 707-710, avr. 1960.

DUVERGER, M. Les deux trahisons. Le Monde, 27 avr. 1960.

FANON, F. Les damnés de la terre. Paris: Maspéro, 1961.

LE DROIT à l'insoumission (le dossier des "121"). Cahiers Libres, F. Mapíro, n. 14, p. 18, 1961.

PÉJU, M. A esquerda respeitosa. Les Temps Modernes, avr./mai 1960.

RICOEUR, P. Entre mémoire et histoire. Projet, n. 248, p. 12, 1996.

RICOEUR, P. História e verdade. Rio de Janeiro: Forense, 1968.

RICOEUR, P. Insoumission. Esprit, p. 1601-1602, oct. 1960.

SARTRE, J-P. Situations V-colonialisme et néo-colonialisme. Paris: Gallimard, 1964.

SILVA, H. R. da. Le discours d'Esprit et des Temps Modernes contre la guerre d'Algerie - réflexions sur le phénomène de l'engagement. Manterre, 1991. Thèse (Doctorat d'Etat) - Université de Paris X.

SILVA, H. R. da. Les temps de l'action. Le discours d'Esprit et des Temps Modernes sur les réseaux de soutien au FLN et les mouvements des insoumis. Hermes, Editions du CNRS, n. 8/9, 1991.

SILVA, H. R. da. Texte, action et histoire - réflexions sur le phénomène de l'engagement. Paris: L'Harmattan, 1995.

SPECTOR, C. Le pouvoir. Paris: Corpus/GF Flammarion, 1997.

WEIL, E. Filosofia política. Paris: Vrin, 1956.

WEIL, E. Logique de la philosophie. 2. ed. Paris: Vrin, 1969. 